\title{
VEGF transcription and mRNA stability are altered by WT1 not DDS(R384W) expression in LNCaP cells
}

\author{
JENNIFER CASH, AMANDA KORCHNAK, JACQUELYN GORMAN, YASMEEN TANDON and GAIL FRAIZER
}

Department of Biological Sciences, Kent State University, Kent, OH 44242, USA

Received December 6, 2006; Accepted January 11, 2007

\begin{abstract}
To identify physiologically relevant WT1 transcriptional target genes in prostate cancer cells, we have established stably transfected LNCaP cell lines expressing either WT1(A), its mutant counterpart DDS(R384W), or vector control. Microarray analyses of these cells revealed that vascular endothelial growth factor (VEGF) was differentially expressed in the engineered lines. Regulation of VEGF by WT1 likely contributes to kidney angiogenesis during development and WT1 mutants such as DDS(R384W) are associated with the Denys-Drash syndrome (DDS), characterized by renal abnormalities. Recent mechanistic studies have demonstrated that the WT1(A) isoform binds VEGF promoter sequences and transcriptionally regulates VEGF reporter constructs. However, regulation of VEGF is complex, involving both transcriptional and post-transcriptional processes. This study examined the ability of hormone and Actinomycin D treatment to alter VEGF mRNA levels in stably transfected WT-LNCaP, DDS-LNCaP, or V-LNCaP prostate cancer cells. The rationale of this study was based on a previous finding that enhancement of VEGF expression in DDS-LNCaP cells occurred only in the presence of the androgen analog, R1881. One possible explanation for these results was that DDS-WT1 stabilized VEGF mRNA so that it accumulated to higher levels. This hypothesis was tested by treating engineered $\mathrm{LNCaP}$ cells with Actinomycin D (Act D) and then measuring VEGF mRNA levels by quantitative real-time PCR. The combined effects of WT1 or DDS(R384W) and hormone were tested in these message stability assays and also in transcription assays of transiently transfected LNCaP cells. The results indicated that DDS-WT1 is unable to regulate VEGF transcription or stabilize VEGF mRNA in LNCaP prostate cancer cells. However our observations are also consistent with wild-type WT1(A) having both transcriptional and post-transcriptional effects on VEGF mRNA levels in the presence of hormone.
\end{abstract}

Correspondence to: Dr Gail Fraizer, Department of Biological Sciences, Kent State University, Kent, OH 44242, USA

E-mail: gfraizer@kent.edu

Key words: vascular endothelial growth factor, Wilms' tumor gene, Denys-Drash syndrome, $\mathrm{LNCaP}$, prostate cancer cells
These studies of VEGF regulation by WT1 and dysregulation by DDS(R384W) suggest an important role for WT1 in both normal and tumor-related angiogenesis.

\section{Introduction}

The Wilms' tumor suppressor gene (WT1) encodes a multifunctional zinc-finger protein with many isoforms. The isoform WT(A) lacking exon 5 and the KTS tripeptide is the transcriptionally active form that either represses or activates transcription, depending upon the gene target and cells tested (1). Mechanistic studies of WT1(A) focus on the role played by zinc fingers 2-4 (reviewed in refs. 2,3) and often compare the WT1(A) isoform to one of the naturally occurring zinc finger mutants associated with the Denys-Drash syndrome (DDS) (4), such as the common mutation DDS(R384W), resulting in an arg to trp substitution in the third zinc finger (2). In an effort to identify genes transcriptionally regulated by WT1 in prostate cancer cells, we have established stably transfected LNCaP cell lines expressing either WT1(A) (WT-LNCaP), the DDS(R384W) mutant (DDS-LNCaP), or vector control (V-LNCaP) (5). Gene expression patterns of these three lines were compared using cDNA microarray analyses (6). Among those genes differentially expressed in the engineered lines was the angiogenesis gene, vascular endothelial growth factor (VEGF).

As a key mediator of angiogenesis, VEGF is tightly regulated at both the transcriptional and post-transcriptional levels. VEGF regulation is complex as it is up-regulated by hypoxia, growth factors, steroid hormones and transcription factors (7). To better understand the regulation of VEGF expression in these stably transfected prostate cancer cells, VEGF mRNA was quantified in hormone-treated cells using real-time quantitative RT-PCR. Surprisingly, VEGF expression was enhanced in LNCaP cells expressing the DDS(R384W) mutant, but only in the presence of the androgen analog, methyltrienolamine (R1881) (6). Based on the observations that VEGF levels were inversely related in the WT1- and DDS-LNCaP lines (relative to V-LNCaP), it was important to determine whether both WT1 and DDS(R384W) might regulate VEGF expression, and if so whether regulation by DDS(R384W) might differ from that mediated by wild-type WT1. Amongst its many functions, the WT1 zinc-finger protein can regulate expression by both DNA and RNA interactions $(2,8)$. Interestingly, the predicted RNA binding domains are unaffected by the arg to trp mutation in the third 
Table I. Forward and reverse primer sequences. ${ }^{a}$

\begin{tabular}{llc}
\hline Gene & \multicolumn{1}{c}{ Primer sequences (5'-3') } & Amplicon (bp) \\
\hline Cyclophilin $^{\text {b }}$ & F: CTC-CTT-TGA-GCT-GTT-TCG-AG & 325 \\
& R: CAC-CAC-ATG-CTT-GCC-ATC-C & \\
VEGF $^{b}$ & F: CGA-AAC-CAT-GAA-CTT-TCT-GC & 302 \\
& R: CCT-CAG-TGG-GCA-CAC-ACT-CC & \\
B-actin $^{\text {c }}$ & F: GTG-GGG-CGC-CCC-AGG-CAC-CA & 540 \\
& R: GTC-CTT-AAT-GTC-ACG-CAC-GAT-TTC & \\
\hline
\end{tabular}

aPrimers used for real-time RT-PCR amplification using SYBR-Green PCR Master Mix and an ABI 7000 (Applied Biosystems, Foster City, CA) as

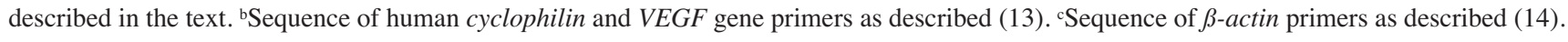

zinc finger of DDS(R384W) and DDS-WT1 retains the ability to bind RNA oligomers (9). Although WT1(A) binds the VEGF promoter and regulates its transcription (10), additional regulatory mechanisms could impact VEGF levels in LNCaP cells. Thus, our hypothesis was that elevated VEGF levels in hormone-treated DDS-LNCaP cells reflected stabilization of VEGF mRNA.

This hypothesis was consistent with the general belief that the DDS(R384W) mutant is transcriptionally dysfunctional (4) and with our observation that in the DDS-LNCaP cells, VEGF levels were only elevated when they were grown in the presence of the androgen analog, methyltrienolamine (R1881) (6). Since VEGF mRNA levels in DDS-LNCaP cells grown in charcoal stripped FCS in the absence of hormone were similar to those in $\mathrm{V}$-LNCaP, we hypothesized that hormone and DDS together might enhance VEGF mRNA stability and thus increase levels detected by real-time RTPCR. This hypothesis was tested by measuring VEGF mRNA levels in Actinomycin D (Act D)-treated WT-, DDS-, and $\mathrm{V}$-LNCaP cells grown in the presence or absence of $5 \mathrm{nM}$ R1881. VEGF mRNA levels were quantified using real-time quantitative PCR (QRT-PCR) and the effects of both Act D and hormone treatments were assessed in each cell line. In addition to message stabilization assays, transcriptional reporter assays were also performed in the presence and absence of hormone. The murine WT1 (A) expression construct and its mutant counterpart, DDS (R384W) (4) were transiently cotransfected, along with several VEGF promoter constructs, in LNCaP cells. Overall, the effects of WT1 and hormone treatment were tested on transcription (measured in transient transfection assays) and on message stability (measured in stably transfected LNCaP cells).

\section{Materials and methods}

Hormone and Actinomycin treatment of cultured cells. LNCaP prostate cancer cells were stably transfected as described previously (5), with the plasmids encoding the transcriptionally active isoform of WT1 (isoform A) or the DDS(R394W) mutant WT1 or pcDNA3.1, the vector. LNCaP cells (ATTC CRL 1740) and three of the engineered cell lines selected and characterized previously (5), were seeded into 6-well plates, and subconfluent monolayers were synchronized by serum starvation for $18 \mathrm{~h}$ prior to incubation in RPMI (BioWhittaker, MD) medium containing $10 \%$ fetal calf serum (FCS). For hormone induction studies RPMI medium was supplemented with $10 \%$ charcoal-dextran stripped fetal calf serum (Ch-FCS) and half of these cultures were also supplemented with $5 \mathrm{nM}$ of the synthetic androgen, R1881 (methyltrienolone), because of its strong affinity for the androgen receptor (11). To measure mRNA stability, $2 \mathrm{~h}$ after release from serum-starvation cells were treated with either 0 or $5 \mu \mathrm{g} / \mathrm{ml}$ Act D. Initially, the effects of 2-h treatment with $5 \mu \mathrm{g} / \mathrm{ml}$ Act D was measured in LNCaP and V-LNCaP cells. Each experiment was performed in triplicate and repeated at least twice. Once the effect of Act D on VEGF levels was determined in V-LNCaP cells, then a time-course study was performed treating WT1-, DDS-, and V-LNCaP cells with Act D for 0, 0.5, 2, and $6 \mathrm{~h}$ prior to RNA isolation.

RNA isolation, reverse transcription and quantitative realtime PCR. RNA was isolated from subconfluent monolayers of cells in 6-well plates by the guanidium isothiocyanate method using the RNAqueous4PCR kit (Ambion, Austin TX) according to the manufacturer's protocol. The optional DNAse treatment step was included after initial RNA isolation. The quality of the RNA was evaluated by electrophoresis on a $0.8 \%$ agarose-formaldehyde denaturing gel (12) and by optical density ratios at 260 and $280 \mathrm{~nm}$. One $\mu \mathrm{g}$ of RNA from each sample was reverse transcribed at $37^{\circ} \mathrm{C}$ for $2 \mathrm{~h}$ using Superscript II (Invitrogen, Carlsbad, CA) and random hexamers (Perkin Elmer, Boston, MA) as described (5).

Quantitative real-time PCR was essentially performed as described (6) using the ABI 7000 and SYBR-Green PCR Master Mix (Applied Biosystems, Foster City, CA). Primer sequences are shown in Table I (F, forward; R, reverse) and amplification was performed using either $150 \mathrm{nM}$ cyclophilin, (13), $150 \mathrm{nM} \beta$-actin (14) or $300 \mathrm{nM}$ VEGF primers (13). The amplification conditions were $95^{\circ} \mathrm{C}$ for $10 \mathrm{~min}, 40$ cycles at $95^{\circ} \mathrm{C}$ for $15 \mathrm{sec}, 60^{\circ} \mathrm{C}$ for $1 \mathrm{~min}$ followed by the dissociation protocol beginning at $60^{\circ} \mathrm{C}$. Quantitative analyses were performed as described (6), in accordance with the manufacturer's recommendations (Applied Biosystems). Relative quantitation of PCR amplified products was determined by 
$\mathrm{dCT}$ analysis as previously described (6) using cyclophilin or $\beta$-actin as the internal reference (normalizer) and comparing RNA obtained from Act D-treated WT1-, DDS- or V-LNCaP cells to untreated cells. Additional assays performed in the presence of $5 \mathrm{nM}$ R1881 were analyzed by comparing R1881treated WT1- or DDS- LNCaP to V-LNCaP cells to untreated cells. Fold-differences were determined by the $2^{\text {-ddCt }}$ method (15), as previously described (6).

LNCaP cell transfections. LNCaP prostate cancer cells were cultured in 12-well plates and transfected as described (16) using lipofectamine 2000 (Invitrogen) in serum- and antibioticfree media. Hormone induction was performed as described above. The cytomegalovirus (CMV) promoter-driven pCMVWT1(A) expression construct encoding the murine Wt1 gene (lacking both KTS insertion and exon 5) and the mutant DDS-WT1(R384W) expression plasmids were previously described $(4,17,18)$. The pGL3-VEGF promoter-luciferase reporter constructs (VEGF 88, 411, 1012, 2274) were obtained from Dr K. Xie (19). All DNA was purified by the Qiagen plasmid Maxi kit (Qiagen, Carlsbad CA). All transfections were performed as described (16). Briefly, $0.25 \mathrm{ug}$ of the stated VEGF promoter-luciferase reporter construct was co-transfected along with 5 ng of pRL-null, the promoterlessRenilla luciferase normalizer (Promega, Madison, WI), and increasing concentrations of the WT1(A) or DDSWT1(R384W) expression constructs $(0,0.25,0.5 \mu \mathrm{g})$. DNA levels were held constant by the addition of the empty CMV expression vector, pCMV4 (Promega). Six hours after DNA transfection, the medium was removed and replaced with fresh RPMI with $10 \%$ FCS. For hormone induction studies RPMI medium contained $10 \%$ charcoal-dextran stripped fetal calf serum (Ch-FCS) and half of the cultures were supplemented with $5 \mathrm{nM}$ of the synthetic androgen, R1881. Cells were harvested at $72 \mathrm{~h}$ and lysates prepared as per manufacturer's recommendations (Promega).

Reporter assays. Initially both firefly and Renilla luciferase activities of the cellular extracts were measured using the Dual-luciferase reporter assay system (Promega) and a 20/20n luminometer (Turner, Sunnyvale, CA). However, since WT1 activated the pRL-null expression vector, as previously described (16), luciferase activity was not normalized using Renilla luciferase activity, but rather by cellular protein concentration. Cellular protein concentration reflects cell viability and controls for variability in numbers of transfected cells (20). The protein concentration of cell extracts was determined using the Micro BCA protein assay reagent kit (Pierce, Rockford, IL), and absorbance was read at $570 \mathrm{~nm}$ on a Dynex Technologies MRX Revelation plate reader (Chantilly, VA). Cellular protein concentrations were relatively constant varying $<25 \%$ between samples. Average protein concentration was determined using a BSA standard and normalized luciferase activity was reported relative to the protein concentration of the cell extracts.

Statistical analysis. Each transfection was performed in triplicate and repeated at least three times. Standard errors of the mean were determined using the GraphPad InStat statistical software program (San Diego, CA). Significance
Table II. Hormone treatment enhanced VEGF mRNA levels in LNCaP cells, but Actinomycin D treatment prevented hormone induction.

Hormone effect

(Relative to $0 \mathrm{nM} \mathrm{R} 1881)^{\mathrm{a}}$

$0 \mu \mathrm{g}^{\mathrm{ActD}} \mathrm{LNCaP} \quad 5 \mu \mathrm{g}^{\mathrm{A}} \mathrm{ActD} \mathrm{LNCaP}^{\mathrm{b}}$

\begin{tabular}{lll}
\hline Normalized cyclophilin $^{\mathrm{c}}$ & $1.80 \mathrm{x} \mathrm{Up}$ & $1.09 \mathrm{x} \mathrm{Up}$ \\
${\text { Normalized } B-\text { actin }^{\mathrm{c}}}$ & $1.90 \mathrm{x} \mathrm{Up}$ & $1.02 \mathrm{x} \mathrm{Up}$ \\
\hline
\end{tabular}

${ }^{a}$ Serum-starved cells were cultured in the presence of $10 \%$ CHS-FCS with or without $5 \mathrm{nM} \mathrm{R} 1881$ prior to Act D treatment. RNA levels were measured by real-time quantitative RT-PCR as described in the text. Relative quantitation of PCR amplified products was determined by $2^{- \text {ddCt }}$ analysis (15) as described in the text. Fold-increase values are shown relative to cells cultured without R1881. berum-starved cells were cultured in the presence of $10 \%$ CHS-FCS with or without $5 \mathrm{nM} \mathrm{R} 1881$ for $2 \mathrm{~h}$ followed by $2 \mathrm{~h}$ of treatment with or without $5 \mathrm{ug} / \mathrm{ml}$ Act D. Fold-increase values were determined as described

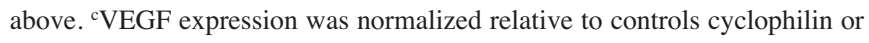
ß-actin.

was determined by one-way analysis of variance (ANOVA) followed by the Tukey-Kramer multiple comparison test.

\section{Results and discussion}

Actinomycin D treatment prevented hormone-induced VEGF expression in LNCaP and V-LNCaP control cells. To confirm that treatment with R1881 induced VEGF expression, LNCaP cells were serum-starved overnight and then half of the cultures were treated for $2 \mathrm{~h}$ with $5 \mathrm{nM} \mathrm{R} 1881$ (and half were cultured in $10 \% \mathrm{ChS}-\mathrm{FCS}$ without R1881). Then $5 \mathrm{ug} / \mathrm{ml} \mathrm{Act}$ $\mathrm{D}$ was added to half of each of these cultures (with or without R1881) to determine whether hormone treatment was inducing VEGF transcription or simply stabilizing message levels. After $2 \mathrm{~h}$ of Act D treatment (or $4 \mathrm{~h}$ total) cells were harvested, RNA isolated and VEGF levels measured by quantitative real-time PCR analysis (QRT-PCR). RNA levels were normalized using two methods; by comparison with cyclophilin or $\beta$-actin expression, using the $2^{\text {-ddCt }}$ method to compare hormonetreated with untreated cells. Four hours of hormone treatment induced a 2-fold increase in VEGF mRNA levels, relative to cells cultured without R1881 (Table II). However, VEGF mRNA levels were not increased by hormone treatment of cells also treated with $5 \mathrm{ug}$ of Act D, as VEGF mRNA remained at levels equivalent to those in cells cultured in $10 \%$ CHFCS without R1881. These results indicated that hormone enhanced transcription was not Act D resistant (and therefore represented newly transcribed mRNA), suggesting that hormone affected transcription, but not message stability.

Before analyzing the effect of WT1 expression on VEGF transcript levels, control LNCaP cells stably transfected with the empty vector (V-LNCaP) were tested and also found to be hormone responsive and Act D sensitive (Table III). As described above for Table II, serum-starved cells were cultured for $2 \mathrm{~h}$ in the presence or absence of $5 \mathrm{nM}$ R1881, followed by culturing in the presence or absence of $5 \mathrm{ug} / \mathrm{ml}$ Act D. VEGF 
Table III. Actinomycin D treatment decreased VEGF mRNA levels in V-LNCaP cells treated with $5 \mathrm{nM} \mathrm{R} 1881$.

\begin{tabular}{|c|c|c|}
\hline & \multicolumn{2}{|c|}{$\begin{array}{c}\text { Act D effect } \\
\left(\text { Relative to } 0 \mu \mathrm{g} \text { Act D) }{ }^{\mathrm{a}}\right.\end{array}$} \\
\hline & 0 nM R1881 ${ }^{\mathrm{b}}$ & 5 nM R1881 \\
\hline Normalized cyclophilin $^{\mathrm{c}}$ & 2.22x Down & 4.03x Down \\
\hline Normalized $\beta$-actin ${ }^{c}$ & 2.13x Down & 3.10x Down \\
\hline \multicolumn{3}{|c|}{$\begin{array}{l}{ }^{\text {aCells }} \text { were treated with } 0 \text { or } 5 \mu \mathrm{g} / \mathrm{ml} \text { Act D following release from serum } \\
\text { starvation, as described in the text. RNA levels were measured by real-time } \\
\text { quantitative RT-PCR and relative quantitation of PCR amplified products } \\
\text { was determined by } 2^{- \text {ddCt }} \text { analysis }(15) \text { as described in the text. Fold-decrease } \\
\text { values are shown relative to cells cultured without Act D. }{ }^{\text {b Serum-starved }} \\
\text { cells were cultured in the presence of } 10 \% \text { CHS-FCS with } 5 \mathrm{nM} \mathrm{R} 1881 \text { for } \\
2 \mathrm{~h} \text { followed by } 2 \mathrm{~h} \text { of treatment with } 0 \text { or } 5 \mu \mathrm{g} / \mathrm{ml} \text { Act D. Fold-decrease } \\
\text { values were determined as described above. }{ }^{\mathrm{c}} \mathrm{VEGF} \text { expression was normalized } \\
\text { relative to controls cyclophilin or } \beta \text {-actin. }\end{array}$} \\
\hline
\end{tabular}

mRNA levels were measured by QRT-PCR and values were normalized by both cyclophilin or $\beta$-actin, using the $2^{\text {-ddCt }}$ method (15) to compare Act D-treated with untreated cells. The effect of Act D on V-LNCaP cells was similar to that on untransfected LNCaP cells, in that VEGF levels were 2 -fold lower relative to cells cultured for $2 \mathrm{~h}$ without R1881 (Table III). The presence of hormone did not prevent the reduction of VEGF mRNA levels by Act D treatment of VLNCaP cells, suggesting increased message stability did not account for the previously observed hormone-mediated elevation of VEGF levels in V-LNCaP cells (6). Indeed the relative reduction of VEGF levels was greater in the presence of hormone, since in the absence of Act D, R1881 increased VEGF levels (Table III).

Actinomycin D reduced VEGF levels in LNCaP cells engineered to express mutant DDS-WT1. Having demonstrated that $2 \mathrm{~h}$ of Act D treatment reduced VEGF mRNA levels two-fold in LNCaP and V-LNCaP cells, it was important to determine whether expression of WT1 or DDS-WT1 in stably transfected LNCaP cells would alter the response to Act D. If the previously observed elevated levels of VEGF in DDS-LNCaP cells (6) were due to mRNA stabilization, as hypothesized, then Act D treatment should have little effect. VEGF mRNA levels were measured first in cells cultured without R1881, to establish a baseline (Fig. 1A), then in cells treated with $5 \mathrm{nM}$ R1881 (Fig. 1B). As expected, Act D treatment reduced VEGF levels two-fold in cells cultured without R1881 (Fig. 1A). In fact, VEGF mRNA levels in DDS-LNCaP cells paralleled those in $\mathrm{V}-\mathrm{LNCaP}$, suggesting that in the absence of hormone, expression of DDS-LNCaP had no significant effect on message stability. This was consistent with previous results showing that VEGF levels increased in DDS-LNCaP cells only when hormone treated (6). Surprisingly, when DDS-LNCaP and Va LNCaP cells were cultured in media containing 5nM R1881, mRNA levels also declined $\geq 2$-fold (Fig. 1B). Thus, the presence of the DDSWT1 protein appeared insufficient to stabilize VEGF mRNA in either the presence or absence of R1881. Interestingly,

\section{VEGF levels decline with Actinomycin D}

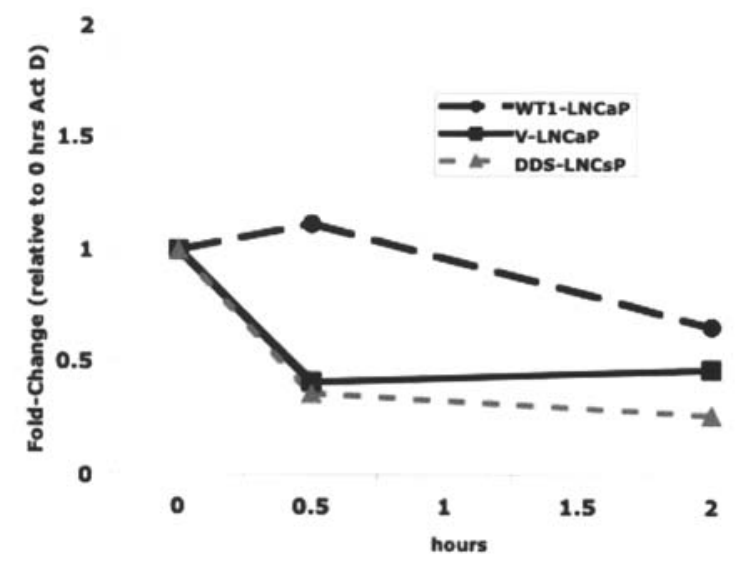

\section{Hormone alters VEGF levels in Actinomycin D treated WT1-LNCaP cells}

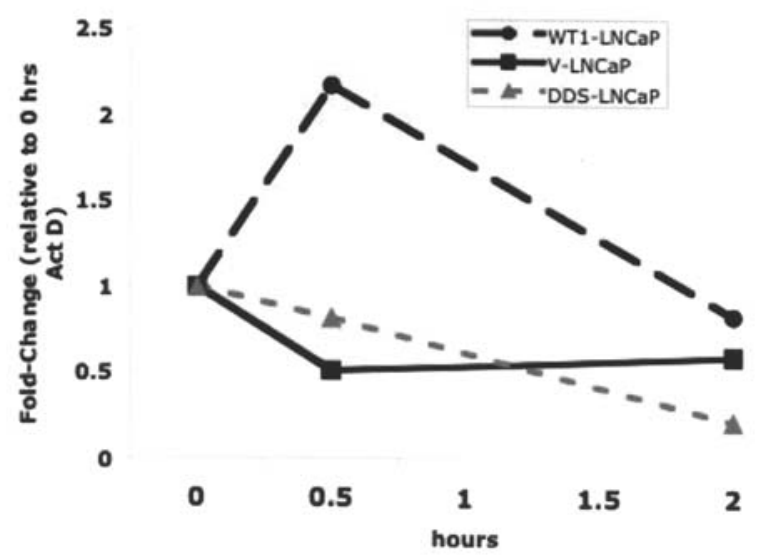

Figure 1. VEGF levels declined with Actinomycin D despite hormone treatment. The effect of Act D treatment was followed in a time-course study of LNCaP cells stably transfected with wild-type WT1 (WT1LNCaP), mutant DDS-WT1 (DDS-LNCaP), or vector control (V-LNCaP). RNA levels were measured by real-time quantitative PCR as described in the text. Relative quantitation of PCR amplified products was determined by $2^{- \text {ddCt }}$ analysis (15) as described (6), using cyclophilin as the normalizer and comparing RNA obtained from Act D-treated WT1-, DDS- or V-LNCaP cells to untreated cells. (A) VEGF levels declined with Act D. Serumstarved cells were cultured in RPMI with $10 \%$ CHS-FCS (without R1881) for $2 \mathrm{~h}$ followed by $0,0.5$ or $2 \mathrm{~h}$ of treatment with $5 \mathrm{ug} / \mathrm{ml}$ Act D. Foldchange values are shown relative to RNA isolated from cells harvested prior to Act D treatment. (B) Hormone altered VEGF levels in WT1-LNCaP cells treated with Act D. Serum-starved cells were cultured in RPMI with $10 \%$ CHS-FCS containing $5 \mathrm{nM} \mathrm{R} 1881$ and treated with Act D as described for A. Fold-change values are shown relative to RNA isolated from cells harvested prior to Act D treatment.

expression of the wild-type WT1 in the absence of R1881 may have slowed the decline in VEGF mRNA levels (Fig. 1A), reaching VEGF levels of the control V-LNCaP cells by $2 \mathrm{~h}$. Additionally, WT1 appeared to transiently stabilize VEGF mRNA levels in R1881-treated cells, as message levels were elevated 2-fold at the 0.5 -h time point and did not decline below baseline, even after 2-h treatment (Fig. 1B). This modest stabilization appeared to be hormone enhanced, as VEGF mRNA levels declined 1.5-fold after $2 \mathrm{~h}$ in the absence of 
VEGF gene promoter contains potential hormone and WT1 responsive sites

A

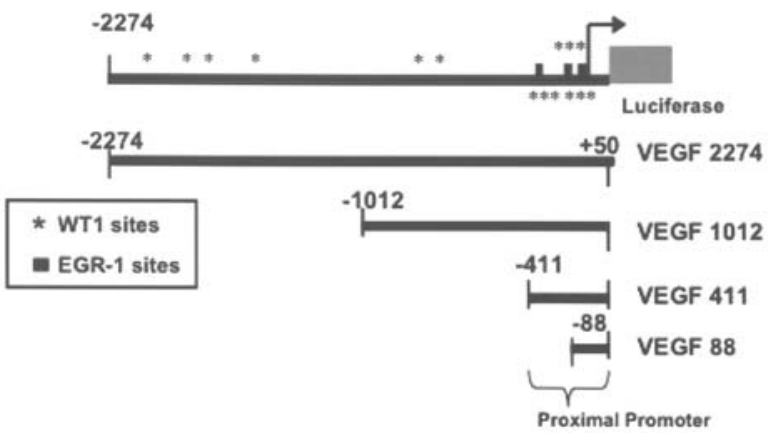

DDS-WT1 does not activate VEGF promoter

vector control

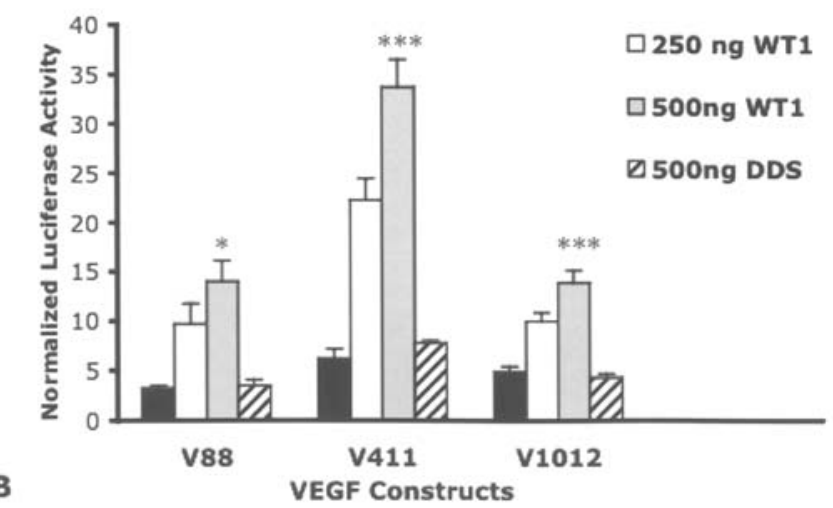

Figure 2. VEGF promoter was activated by transfection of murine WT1(A) but not by DDS-WT1(R384W) mutant. (A) VEGF promoter has multiple WT1 binding sites. Proximal promoter region has both WT1 and EGR-1 sites to which WT1 could potentially bind. Two sites have been verified to bind WT1 protein, one in the VEGF 88 region and one in the 5 ' region of the VEGF 411 construct (adapted from ref. 10, not drawn to scale). (B) DDSWT1(R384W) is not transcriptionally active in LNCaP cells. Wild-type WT1 or DDS-WT1(R384W) mutant or empty control vector was co-transfected along with a given VEGF-luciferase reporter construct (V88, V411, or V1012) in LNCaP cells. Cells were co-transfected with increasing amounts of WT1: $0 \mathrm{ng}$ (black), $250 \mathrm{ng}$ (white), or $500 \mathrm{ng}$ (grey); or $500 \mathrm{ng}$ of DDSWT1(R384W) (striped). DNA levels were held constant by transfecting pCMV4 empty vector control DNA. Each experiment was performed in triplicate and repeated three times. Luciferase activity was normalized as described in the text and is shown \pm SEM. Significance was determined by ANOVA $\left({ }^{*} \mathrm{p}<0.005,{ }^{* *} \mathrm{p}<0.001,{ }^{* * *} \mathrm{p}<0.0001\right)$.

R1881 (Fig. 1A). Taken together, these results suggest that DDS-WT1 is unable to stabilize VEGF mRNA whether in the presence or absence of hormone, but hormone transiently enhanced VEGF stability in those cells expressing WT1. Thus, a functional zinc finger domain might enhance VEGF message stability in the presence of hormone.

DDS-WT1 did not regulate VEGF transcription. Given that elevated VEGF mRNA levels could not be explained by message stabilization in hormone-treated DDS-LNCaP cells, it was important to determine whether the DDS-WT1 mutant had some residual transcriptional activity that could account for increased transcription initiation. Thus, reporter assays were performed in LNCaP cells transiently transfected with
R1881 treatment does not alter DDS-WT1 inactivity

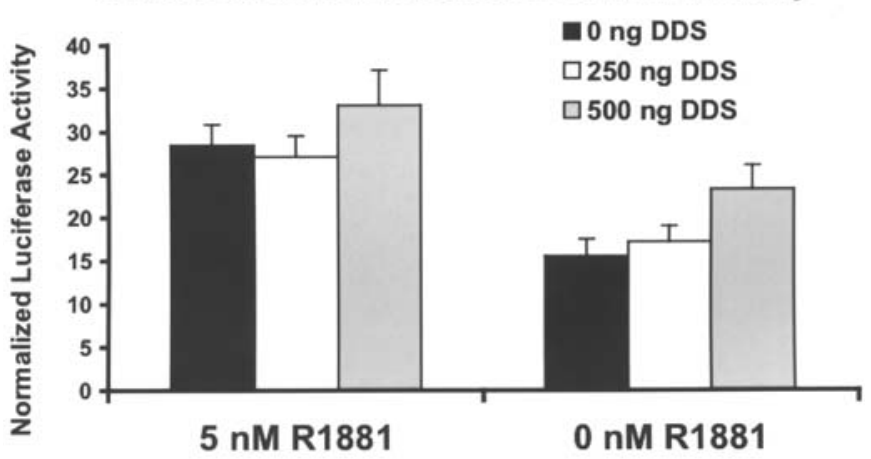

Figure 3. DDS-WT1(R384W) did not activate the full-length VEGF promoter, VEGF 2274, even with hormone R1881 treatment. LNCaP cells were co-transfected with the full-length VEGF promoter, VEGF 2274, and increasing amounts of DDS-WT1(R384W): $0 \mathrm{ng}$ (black), $250 \mathrm{ng}$ (white), or $500 \mathrm{ng}$ (grey). DNA levels were held constant as described in Fig. 2. Cells were cultured in RPMI-10\% ChS-FCS after co-transfection and treated with either 0 or $5 \mathrm{nM} \mathrm{R} 1881$ for $72 \mathrm{~h}$ prior to harvesting. The luciferase values were normalized as described in the text and are shown \pm SEM. Each experiment was performed in quadruplicate and repeated three times. Transfection of DDS-WT1(R384W) had no significant effect, as determined by ANOVA.

the DDS-WT1(R384W) mutant and several VEGF promoter constructs (Fig. 2A). Previous results demonstrated that the proximal VEGF promoter region (contained within the VEGF 88 and VEGF 411 constructs) was transcriptionally activated by WT1 and two functional DNA binding sites were located within this proximal promoter region (10). The aim here, was to determine the importance of the zinc finger DNA binding domain in regulating transcription of the proximal promoter region, since the DDS-WT1 (R384W) mutant has an altered DNA binding domain and was not expected to bind DNA (4). The WT1 mutant DDS-WT1(R384W) expression construct was derived from a murine WT1 gene, and so was compared to the wild-type murine WT1(A) expression construct. A similar up-regulation of the proximal VEGF promoter constructs, VEGF 88 and VEGF 411, was observed when the murine WT1 was transfected into LNCaP cells (Fig. 2B). WT1 (500 ng) increased the activity of VEGF 88 and VEGF 411 4.3- and 4.9-fold, respectively, in LNCaP cells. WT1 also increased the activity, though to a lesser extent, of the larger VEGF promoter construct that included the more distal regions, VEGF 1012 (2.5-fold). Activation of these VEGF promoter constructs was considered significant as determined by ANOVA ( $\mathrm{p}=0.0024, \mathrm{p}<0.0001$ and $\mathrm{p}<0.0001$, for VEGF-88, -411 , and -1012 , respectively). Since the murine WT1 gene behaved similarly to the human gene in LNCaP cells, this strengthened the conclusion that the lack of activation of VEGF reporter constructs by DDS-WT1 was due to the zinc finger mutation. The inactivity of the DDS-WT1(R384W) construct was confirmed in two other cell lines, HEK-293 kidney cells and PC3 prostate cancer cells, as well (data not shown). Overall, this suggested that the DNA binding domain of WT1 plays an essential role in the transcriptional regulation of VEGF.

While no dimeric androgen receptor binding site has been identified in the VEGF promoter, we and others have observed that the VEGF promoter is androgen responsive $(10,21-23)$. 
Since R1881 increases the transcriptional activitation of the VEGF promoter by wild-type WT1 (10), it was important to determine whether hormone could also enhance activation by DDS-WT1. Therefore, the combined effects of $5 \mathrm{nM}$ R1881 and increasing amounts of DDS-WT1 were tested on the fulllength VEGF promoter containing several hormone responsive vitamin D, estrogen, and ER- $\alpha / \mathrm{SP} 1$ composite sites $(24,25)$. Transiently transfected DDS-WT1 failed to activate the fulllength VEGF promoter, whether cells were treated with R1881 or left untreated (Fig. 3). In contrast to our previous studies showing hormone-enhanced WT1 activity $(10,16)$, R1881 did not enhance the activity of DDS-WT1.

Importance of VEGF regulation by WT1 and DDS-WT1. Overall, these results indicated that DDS-WT1 was unable to regulate the transcription of the VEGF promoter, or stabilize VEGF mRNA transcripts. If such inactivity occurred during development, it could potentially contribute to angiogenesis defects. Recent studies of angiogenesis in murine kidney cultures demonstrate that WT1 stimulates growth and nephrogenesis by inducing vegfa in metanephric mesenchyme (26). WT1 is essential for kidney development (27-29) and is co-expressed with VEGF in normal kidney cells and in some Wilms' tumors $(26,29-31)$. In contrast, expression of the DDS-WT1 mutant is associated with the DDS syndrome, characterized by kidney malformations (along with renal mesangial sclerosis, genital anomalies and elevated risk of Wilms' tumor) (4). For both developmental and cancer studies it is important to elucidate the mechanisms whereby WT1 regulates VEGF and thereby, angiogenesis. Taken together, all of these studies suggest that VEGF is a physiologically relevant target of WT1 regulation in several different tissues, including prostate. VEGF expression is elevated in prostate cancer cells (32) and WT1 mRNA has been observed in some cultured prostate cancer cells and tissue samples $(17,33,34)$ (Brown K, and Fraizer G, unpublished data). The finding that WT1 can regulate VEGF in prostate cancer cells (10) is consistent with its ability to regulate several other prostate cancer growth control pathways $(17,18,35-41)$, including the IGF axis. In fact, many of the growth factors that affect VEGF levels are themselves regulated by WT1 $(35,36,42-45)$. Interestingly, the insulin-like growth factor I receptor (IGF-1R) has also been reported to respond to DDS-WT1 co-transfection (46). One possibility is that DDS-WT1 could indirectly affect VEGF expression by regulating IGF-1R expression. This potential activity retained by DDS-WT1 might explain why VEGF levels were increased in the stably transfected DDSLNCaP cells (6), although no transcriptional activity was detected in the transient transfection assays.

Although the different functions of the WT1 zinc-finger isoforms are still being identified, it is clear that WT1 can regulate expression by both DNA and RNA interactions $(2,8)$. Indeed, both the WT1 (-KTS) isoform and the WT1-DDS mutant bind RNA oligomers $(9,47,48)$. Since the 3'UTR of VEGF transcript has a C-rich region that binds RNA stabilizing proteins $(49,50)$ and binding of RNA stabilizing proteins is androgen responsive, it seemed reasonable that DDS might enhance R1881-mediated stabilization of VEGF mRNA. Surprisingly our observations are consistent with wild-type WT1, but not DDS-WT1, enhancing mRNA stability.

\section{Acknowledgments}

We gratefully acknowledge receipt of the VEGF luciferase constructs from Dr K. Xie and the DDS-WT1 constructs from Dr J. Pelletier. These studies were supported by the NIH (R15CA113360) and the Kent State University Research Council.

\section{References}

1. Reddy JL and Licht J: The WT1 Wilms' tumor suppressor gene: how much do we really know? BBA 1287: 1-28, 1996.

2. Mrowka C and Schedl A: Wilms' tumor suppressor gene WT1: From structure to renal pathophysiologic features. J Am Soc Nephrol 11: S106-S115, 2000

3. Roberts S: Transcriptional regulation by WT1 in development. Curr Opin Genet Dev 15: 542-547, 2005.

4. Pelletier J, Bruening W, Kashtan CE, Mauer SM, Manivel JC, Striegel JE, Houghton DC, Junien C, Habib R and Fouser L: Germline mutations in the Wilms' tumor suppressor gene are associated with abnormal urogenital development in DenysDrash syndrome. Cell 67: 437-447, 1991.

5. Fraizer GC, Leahy R, Priyadarshini S, Graham K, Delacerada J and Diaz M: Suppression of prostate tumor cell growth in vivo by WT1, the Wilms' tumor suppressor gene. Int J Oncol 24: 461-471, 2004.

6. Graham K, Li W, Williams BRG and Fraizer G: Vascular endothelial growth factor (VEGF) is suppressed in WT1transfected LNCaP cells. Gene Expr 13: 1-14, 2006.

7. Josko J and Mazurek M: Transcription factors having impact on vascular endothelial growth factor (VEGF) gene expression in angiogenesis. Med Sci Monit 10: RA89-RA98, 2004.

8. Ladomery MR, Sommerville J,Woolner S, Slight J and Hastie ND: Expression in Xenopus Oocytes shows that WT1 binds transcripts in vivo, with a central role for zinc finger one. J Cell Sci 116: 1539-1549, 2002.

9. Zhai G, Iskandar M, Barilla K and Romaniuk P: Characterization of RNA aptamer binding by the Wilms' tumor suppressor protein WT1. Biochemistry 40: 2032-2040, 2001.

10. Hanson J, Gorman J, Reese J and Fraizer G: Regulation of vascular endothelial growth factor, VEGF, gene promoter by the tumor suppressor, WT1. Front Biosci 12: 2279-2290, 2007.

11. Brown TR, Rothwell SW and Migeon CJ: Comparison of methyltrienolone and dihydrotestosterone binding and metabolism in human genital skin fibroblasts. J Steroid Biochem 14: 1013-1022, 1981 .

12. Sambrook J, Fritsch EF and Maniatis T: Molecular Cloning: A Laboratory Manual. 2nd edition. Cold Spring Harbor, New York, 1989.

13. Simpson D, Feeney S, Boyle C and Stitt A: Retinal VEGF mRNA measured by SYBR Green I fluorescence: A versatile approach to quantitative PCR. Mol Vision 6: 178-183, 2000.

14. Patmasiriwat $P$, Fraizer G, Kantarjian H and Saunders GF: WT1 and GATA1 expression in myelodysplastic syndrome and acute leukemia. Leukemia 13: 891-900, 1999.

15. Livak K and Schmittgen TD: Analysis of relative gene expression data using realtime quantitative PCR and the 2-ddCt method. Methods 25: 402-408, 2001.

16. Hanson J, Reese J, Gorman J, Cash J and Fraizer G: Hormone treatment enhances WT1 activation of Renilla luciferase constructs in LNCaP cells. Front Biosci 12: 1387-1394, 2007.

17. Zaia A, Fraizer GC, Piantanelli L and Saunders GF: Transcriptional regulation of the androgen signaling pathway by the Wilms' tumor suppressor gene WT1. Anticancer Res 21: 1-10, 2001.

18. Shimamura R, Fraizer GC, Trapman J, Lau YC and Saunders GF: The Wilms' tumor gene WT1 can regulate genes involved in sex determination and differentiation: SRY, Mullerianinhibiting substance, and the androgen receptor. Clin Cancer Res 3: 2571-2580, 1997.

19. Shi Q, L. X., Abbruzzese JL, Peng Z, Qian C-N, Tang H, Xiong Q, Wang B, Li X-C and Xie K: Constitutive Sp1 activity is essential for differential constitutive expression of vascular endothelial growth factor in human pancreatic adenocarcinoma. Cancer Res 61: 4143-4154, 2001. 
20. Sims RJ, Liss AJ and Gottlieb PD: Normalization of luciferase reporter assays under conditions that alter internal controls. Biotechniques 34: 938-940, 2003.

21. Sordello S, Bertrand N and Plouet J: Vascular endothelial growth factor is up-regulated in vitro and in vivo by androgens. Biochem Biophys Res Commun 251, 1998.

22. Aslan G, Cimen S, Yorukoglu K, Tuna B, Sonmez D, Mungan U and Celebi I: Vascular endothelial growth factor expression in untreated and androgen-deprived patients with prostate cancer. Pathol Res Pract 201: 593-598, 2005.

23. Stewart RJ, Panigrahy D, Flynn E and Folkman J: Vascular endothelial growth factor expression and tumor angiogenesis are regulated by androgens in hormone responsive human prostate carcinoma: Evidence for androgen dependent destabilization of vascular endothelial growth factor transcripts. J Urol 165: 688-693, 2001.

24. Stoner M, Wormke M, Saville B, Samudio I, Qin C, Abdelrahim $M$ and Safe S: Estrogen regulation of vascular endothelial growth factor gene expression in ZR-75 breast cancer cells through interaction of estrogen receptor a and SP proteins. Oncogene 23: 1052-1063, 2004.

25. Mueller MD, Vigne J-L, Minchenko A, Lebovic DI, Leitman DC and Taylor RN: Regulation of vascular endothelial growth factor (VEGF) gene transcription by estrogen receptors $\mathrm{a}$ and $\mathrm{b}$. Proc Natl Acad Sci USA 97: 10972-10977, 2000.

26. Gao X, Chen X, Taglienti M, Rumballe B, Little M and Kreidberg J: Angioblast-mesenchyme induction of early kidney development is mediated by Wt1 and Vegfa. Development 132: 5437-5449, 2005.

27. Hammes A, Guo JK, Lutsch G, Leheste JR, Landrock D, Ziegler U, Gubler MC and Schedl A: Two splice variants of the Wilms' tumor 1 gene have distinct functions during sex determination and nephron formation. Cell 106: 319-329, 2001.

28. Kreidberg J, Sariola H, Loring J, Maeda M, Peletier J, Housman D and Jaenisch R: WT1 is required for early kidney development. Cell 74: 679-691, 1993.

29. Armstrong JF, Pritchard-Jones K, Bickmore WA, Hastie ND and Bard JBL: The expression of the Wilms' tumor gene, WT1, in the developing mammalian embryo. Mech Develop 40: 85-97, 1992.

30. Karth J, Ferrer F, Perlman E, Hanrahan C, Simons JW, Gearhart JP and Rodriguez R: Coexpression of hypoxia-inducible factor 1-alpha and vascular endothelial growth factor in Wilms' tumor. J Pediatr Surg 35: 1749-1753, 2000.

31. Baudry D, Faussillon M, Cabanis M, Rigolet M, Zucker J, Patte C, Sarnacki S, Boccon-Gibod L, Junien C and Jeanpierra C: Changes in WT1 splicing are associated with a specific gene expression profile in Wilms' tumour. Oncogene 21: 5566-5573, 2002.

32. Mazzucchelli R, Montironi R, Santinelli A, Lucarinia G, Pugnaloni A and Biagini G: Vascular endothelial growth factor expression and capillary architecture in high-grade PIN and prostate cancer in untreated and androgen-ablated patients. Prostate 45: 72-79, 2000.

33. Dong G, Rajah T, Vu T, Hoffman A, Rosenfeld R, Roberts C, Peehl D and Cohen P: Decreased expression of Wilms' tumor gene WT-1 and elevated expression of insulin growth factor-II and type 1 IGF receptor genes in prostatic stromal cells from patients with benign prostatic hyperplasia. J Clin Endocrinol Metab 82: 2198-2203, 1997.

34. Dechsukhum C, Ware JL, Ferreira-Gonzalez A, Wilkinson DS and Garrett CT: Detection of a novel truncated WT1 transcript in human neoplasia. Mol Diagn 5: 117-128, 2000.
35. Drummond IA, Madden SL, Rohwer-Nutter P, Bell GI, Sukhatme VP and Rauscher F III: Repression of the insulin-like growth factor II gene by the Wilms' tumor suppressor WT1. Science 257: 674-678, 1992.

36. Werner H, Rauscher FJ, Sukhatme VP, Drummond IA, Roberts CT and Leroith D: Transcriptional repression of the insulin-like growth factor I receptor (IGF-IR) gene by the tumor suppressor WT1 involves binding to sequences both upstream and downstream of the IGF-I-R gene transcription start site. J Biol Chem 269: 12577-12582, 1994.

37. Cheema SK, Mishra SK, Rangnekar VM, Tari AM, Kumar R and Lopez-Berestein G: Par-4 transcriptionally regulates Bcl-2 through WT1-binding site on the Bcl-2 promoter. J Biol Chem 278: 19995-20005, 2003

38. Hewitt S, Hamada S, McDonnell T, Rauscher F and Saunders GF: Regulation of the Proto-oncogenes bcl-2 and c-myc by the Wilms tumor suppressor gene WT1. Cancer Res 55: 5386-5389, 1995.

39. Heckman C, Mochon E, Arcinas M and Boxer L: The WT1 protein is a negative regulator of the normal bcl-2 allele in $\mathrm{t}(14 ; 18)$ lymphomas. J Biol Chem 272: 19609-19614, 1997.

40. Morrison DJ, English MA and Licht JD: WT1 induces apoptosis through transcriptional regulation of the proapoptotic Bcl-2 family member Bak. Cancer Res 15: 8174-8182, 2005.

41. Johnstone RW, See RH, Sells SF, Wang J, Muthukkumar S, Englert C, Haber DA, Licht JD, Sugrue SP, Roberts T, Rangnekar VM and Shi Y: A novel repressor, par-4, modulates transcription and growth suppression functions of the Wilms' tumor suppressor WT1. Mol Cell Biol 16: 6945-6956, 1996.

42. Gashler AL, Bonthron DT, Madden SL, Rauscher FJ, Collins T and Sukhatme VP: Human platelet-derived growth factor A chain is transcriptionally repressed by the Wilms tumor suppressor WT1. Proc Natl Acad Sci USA 89: 10984-10988, 1992.

43. Wang ZY, Madden SL, Deuel TF and Rauscher F III: The Wilms' tumor gene product, WT1, represses transcription of the platelet-derived growth factor A-chain gene. J Biol Chem 267: 21999-22002, 1992.

44. Dey BR, Sukhatme VP, Roberts AB, Sporn MB, Rauscher FJ and Kim S-J: Repression of the transforming growth factorbeta-1 gene by the Wilms' tumor suppressor WT1 gene product. Mol Endocrinol 8: 595-602, 1994.

45. Englert C, Hou X, Maheswaran S, Bennett P, Ngwu C, Re GG, Garvin AJ, Rosner MR and Haber DA: WT1 suppresses synthesis of the epidermal growth factor receptor and induces apoptosis. EMBO J 14: 4662-4675, 1995.

46. Tajinda K, Carroll J and Roberts CT Jr: Regulation of insulinlike growth factor I receptor promoter activity by wild-type and mutant versions of the WT1 tumor suppressor. Endocrinology 140: 4713-4724, 1999.

47. Caricasole A, Duarte A, Larsson SH, Hastie ND, Little M, Holmes G, Todorov I and Ward A: RNA binding by the Wilms tumor suppressor zinc finger proteins. Proc Natl Acad Sci USA 93: 7562-7566, 1996

48. Bardeesy $\mathrm{N}$ and Pelletier J: Overlapping RNA and DNA binding domains of the WT1 tumor suppressor gene product. Nucleic Acids Res 26: 1784-1792, 1998

49. Onesto C, Berra E, Grepin R and Pages G: Poly(A)-binding protein-interacting protein 2 , a strong regulator of vascular endothelial growth factor mRNA. J Biol Chem 279: 34217-34226, 2004

50. Shih S-C and Claffey KP: Regulation of human vascular endothelial growth factor mRNA stability in hypoxia by heterogeneous nuclear ribonucleoprotein L. J Biol Chem 274: 1359-1365, 1999. 